\title{
O "ENCOLHIMENTO" DAS SOMBRAS
}

Fernando Lang da Silveira

Maria de Fátima Oliveira Saraiva

Instituto de Física - UFRGS

Porto Alegre - RS

\section{Resumo}

Quando um objeto intercepta a luz do Sol, a sua sombra sobre um anteparo diminui de tamanho à medida que aumenta a distância entre ele e o objeto. Finalmente, a uma distância grande comparada com as dimensões do objeto, a sombra deixa de existir. Apesar de o efeito ser bem conhecido no contexto da Astronomia, relacionado aos eclipses do Sol e da Lua, ele surpreende a nossa intuição quando produz silhuetas deformadas de objetos conhecidos. Neste artigo, apresentamos uma explicação para este sutil efeito, baseada na Óptica Geométrica. Abordamos também a questão das sombras nos eclipses da Lua e do Sol.

Palavras-chave: Sombras; Óptica Geométrica; eclipses.

\begin{abstract}
When sunlight strikes an opaque object, the cast shadow gets smaller as its distance to the object increases. For distances much greater than the object dimensions the shadow is null. In spite of this effect being well-known in the astronomical context, related to Solar and Lunar eclipses, it surprises our intuition when it produces deformed images of familiar objects. In this article, we give an explanation for this subtle effect based on Geometric
\end{abstract}

\footnotetext{
+ The "shrinking" of the shadows

* Recebido: fevereiro de 2008.

Aceito: junho de 2008.
} 
Optical. We also deal with the question of shadows in Solar and

Lunar eclipses.

Keywords: Shadows; Geometric Optics; eclipses.

\section{Introdução}

As sombras encantam a humanidade, instigando nossa curiosidade, desde épocas remotas, como bem relata Casati (2001). Elas também foram usadas como instrumentos epistemológicos, possibilitando, em ocasiões variadas, o avanço do conhecimento científico. Por exemplo:

- Na Antiguidade, Aristóteles ${ }^{1}$ (384-322 a.C.) utilizou a sombra da Terra sobre a Lua, durante eclipses lunares, como um dos argumentos a favor da esfericidade da Terra; Aristarco de Samos ${ }^{2}$ (320-250 a.C.) usou a sombra da Terra sobre a Lua, para determinar as dimensões cosmológicas e Eratóstenes de Cirene ${ }^{3}$ (270-190 a.C.) usou a sombra de uma estaca, na medida da circunferência da Terra.

- Os atrasos nos eclipses dos satélites de Júpiter permitiram, em 1676, que Römer (1644-1710) provasse, pela primeira vez, a finitude da velocidade da luz.

- O eclipse do Sol possibilitou, em 1868, que Lockyer (1836-1920) identificasse um elemento até então desconhecido - o hélio - no espectro da cromosfe-

\footnotetext{
1 Aristóteles usou dois argumentos a favor da esfericidade da Terra: o primeiro é que a borda da sombra da Terra, projetada sobre a Lua durante eclipses, é sempre circular; o segundo é que, quando uma pessoa se move de norte para sul na superfície da Terra, as estrelas mudam sua posição em relação ao horizonte (BERRY, 1961; HOSKIN, 1999).

Para calcular os tamanhos e as distâncias que o Sol e a Lua estão da Terra, Aristarco parte de seis hipóteses (Heath, 1981; p. 353). A hipótese 5 afirma que o diâmetro do cone de sombra da Terra, quando a Lua o atravessa (eclipse total da Lua), é duas vezes o diâmetro da Lua.

Eratóstenes, o bibliotecário da grande coleção de manuscritos de Alexandria, mediu a extensão da sombra que uma estaca, cravada verticalmente sobre o solo horizontal de Alexandria, tinha ao meio-dia num dia em que o Sol estava no zênite na cidade Siene (Verdet, 1991). Pelo comprimento da sombra, inferiu que o ângulo subtendido pelo arco de circunferência que separa as duas cidades (Siene se situa ao sul de Alexandria) era aproximadamente $7^{\circ}$ e, conhecida a distância entre as duas cidades (Alexandre o Grande havia mandado medir os caminhos do Egito), determinou a circunferência da Terra.
} 
ra solar. Em 1919, um eclipse do Sol permitiu que Eddington (1882-1944) realizasse a observação do desvio da luz de uma estrela pela massa do Sol, conforme previa a Teoria da Relatividade Geral.

O uso correto das sombras em pinturas é essencial para dar a impressão de tri-dimensionalidade, o que é conhecido há séculos por artistas (KNILL et al, 1997). Por outro lado, a falta de conhecimento sobre as sutilezas da sombra pode levar a interpretações erradas de fotografias reais. Como exemplos podemos citar o caso da "face em Marte" (NASA, 1998) ${ }^{4}$, em que sombras causadas por reentrâncias em uma rocha marciana lhe deram a aparência de uma cabeça humana, o que foi usado como indicativo de que seria uma rocha construída artificialmente, e o caso da "farsa da Lua" (MoonHoax, 2003), em que diferenças nas direções e comprimentos das sombras dos astronautas, sondas lunares e rochas da superfície lunar foram usadas como "evidência" de que as fotos da pousada do homem na Lua seriam montagens. Esses fatos, de certa forma pitorescos, contribuem para incentivar o interesse e a curiosidade a respeito das sombras e do comportamento da luz.

Quando crianças, encantamo-nos com as sombras das mãos em uma parede, reproduzindo as silhuetas de animais e objetos variados, que a nossa mente infantil conseguia imaginar. O tamanho das sombras, que víamos na parede, podia ser facilmente aumentado ou diminuído pela modificação da posição da chama da vela e/ou das mãos em relação à parede. Da nossa experiência com sombras produzidas por fontes luminosas artificiais (lâmpadas, velas, etc.), inferimos que, quanto mais distante se encontra o objeto do local onde vemos a sua sombra, tanto maior ela é. A fotografia da Fig. 1 demonstra como, facilmente, a sombra de uma mão se agiganta no teto de uma sala.

\footnotetext{
4 A "face em Marte" foi vista pela primeira vez em fotos tiradas pela sonda Viking I, em 1996 (NASA, 1998), e foi inicialmente divulgada como sendo uma formação rochosa lembrando uma face humana. Novas imagens da mesma rocha, tiradas em 1998 pela sonda Mars Global Surveyor (MSSS, 2001), de um ângulo diferente, não apresentaram a tal semelhança, indicando que a aparência de face humana dependia da iluminação e do ângulo de visada.

5

Os defensores da "farsa da Lua" usam argumentos equivocados e refutáveis, pois as diferenças nos ângulos e comprimentos dessas sombras são perfeitamente explicadas por efeitos de perspectiva e de ondulações na superfície lunar.
} 


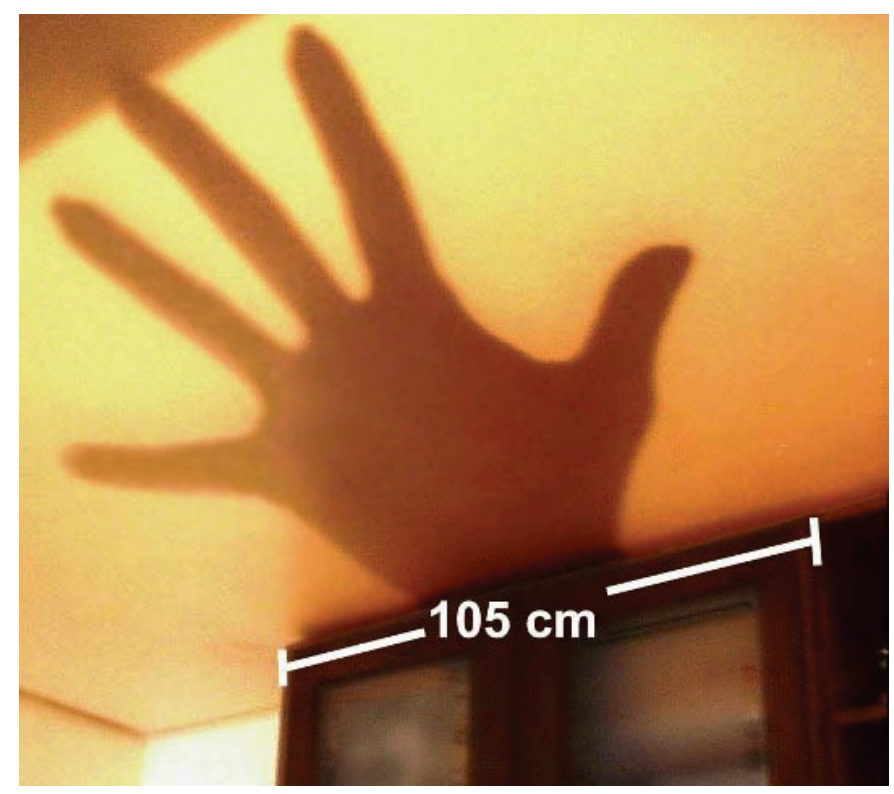

Fig. 1 - Sombra da mão no teto da sala.

Quando um objeto intercepta a luz do Sol, surpreendentemente para a nossa intuição, o tamanho da sombra não cresce quando a distância entre ela e o objeto aumenta. Aumentando a distância, ocorrem deformações na sombra, "encolhendo-a" e, finalmente, fazendo com que ela desapareça. A Fig. 2 mostra duas fotos da sombra da mesma pessoa, sendo que na foto da esquerda o sujeito encontra-se próximo à parede onde vemos sua sombra; na foto da direita a sombra está acontecendo em uma parede distante cerca de $7 \mathrm{~m}$ do sujeito. Observa-se que a sombra mais distante do sujeito encontra-se deformada. A região do pulso da pessoa quase desapareceu, percebendo-se ali apenas penumbra. Uma auréola de penumbra contorna toda a sombra da direita, enquanto que na sombra da esquerda essa borda de penumbra é quase indiscernível.

O objetivo deste artigo é dar uma explicação, baseada na Óptica Geométrica, para o efeito de "encolhimento" da sombra ocasionada pela luz do Sol, à medida que aumenta a distância entre a sombra e o corpo que barra os raios luminosos. Após destacar (seção 2) as diferenças importantes relacionadas com a extensão relativa fonte-objeto, abordamos (seção 3) as sombras de objetos na Terra, iluminados pelo Sol, reservando a seção 4, para explicar o efeito do "encolhimen- 
to" da sombra; na seção 5 mostramos como esse efeito é bem notável nos eclipses solares e lunares.

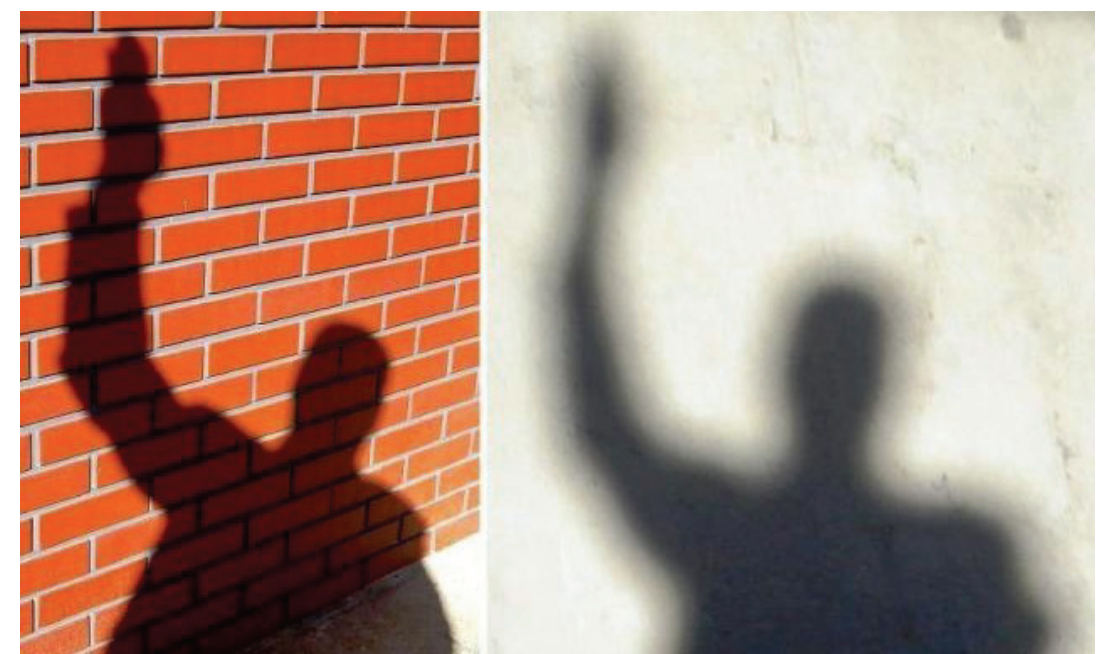

Fig. 2 - A sombra da esquerda está próxima ao sujeito e a sombra da direita se encontra a cerca de $7 \mathrm{~m}$ do sujeito que intercepta a luz solar.

\section{A geometria da sombra depende da extensão relativa fonte-objeto}

Quando um objeto opaco (obstáculo para a luz da fonte) intercepta os raios provindos de uma fonte luminosa, a região tridimensional atrás deste objeto é denominada região de sombra. Esta região não é visível, a menos que seja interceptada por um anteparo (uma superfície qualquer que reflita a luz de forma nãoespecular). Nesse caso, o que se vê sobre o anteparo é a seção transversal da região de sombra, e a esta denomina-se simplesmente sombra. A seguir, trataremos da geometria das sombras quando a fonte luminosa é pontual e quando é extensa.

\section{II.1 Sombras produzidas por fontes pontuais}

Fontes de luz pontuais sempre produzem sombras simples, de bordas bem definidas, como ilustrado nas Fig. 3 e 4.

Se a fonte estiver a uma distância finita, seus raios chegam de direções divergentes a diferentes pontos do objeto opaco (obstáculo), e as bordas da região de sombra se abrem a partir dele (Fig. 3) de forma que, ao incidir sobre um anteparo, 
a sombra será sempre maior do que o objeto, sendo tanto maior quanto maior for a distância entre o anteparo e o objeto opaco (obstáculo), e quanto menor for a distância entre este e a fonte.

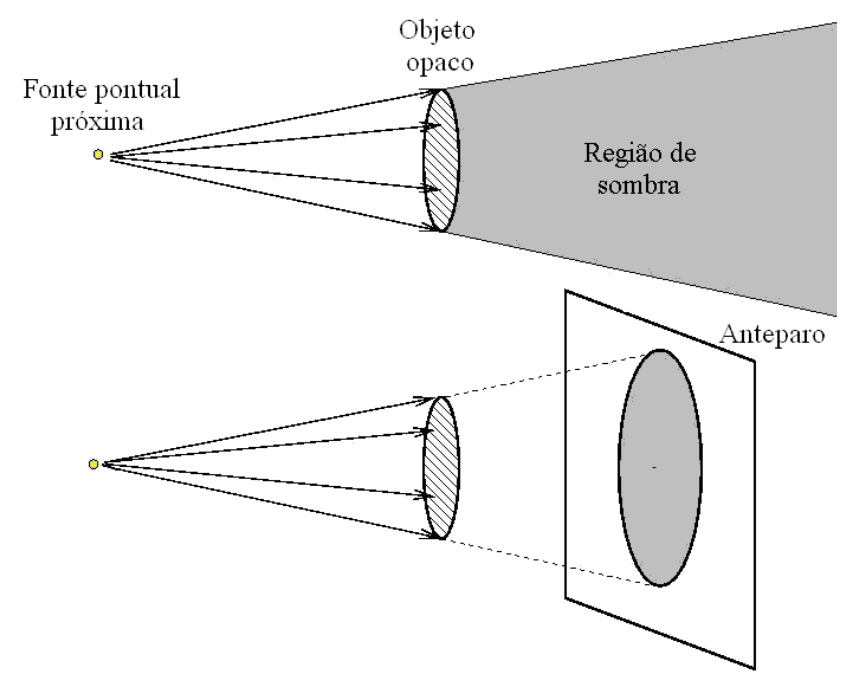

Fig. 3 - Sombra produzida por uma fonte pontual próxima: a região de sombra e a sua seção transversal, como aparece ao incidir a luz da fonte em um anteparo. A sombra é tanto maior quanto mais distante do anteparo estiver o objeto opaco, e quanto mais próxima deste se encontrar a fonte.

À medida que aumenta a distância da fonte ao objeto opaco, os raios luminosos que chegam a ele tornam-se menos divergentes, até que, no limite em que essa distância for infinita (isto é, muito maior do que as dimensões do objeto opaco e do que a distância que separa o objeto do anteparo), a direção dos raios luminosos provenientes da fonte será a mesma para diferentes pontos do objeto nos quais incidem, isto é, os raios de luz provindos da fonte chegarão paralelos a todos os pontos desse objeto. Nesse caso, tal como representado na Fig. 4, as bordas da região de sombra são paralelas e, ao ser interceptada por um anteparo, a sombra produzida terá tamanho igual ao do objeto, independentemente da distância entre ele e o anteparo. 

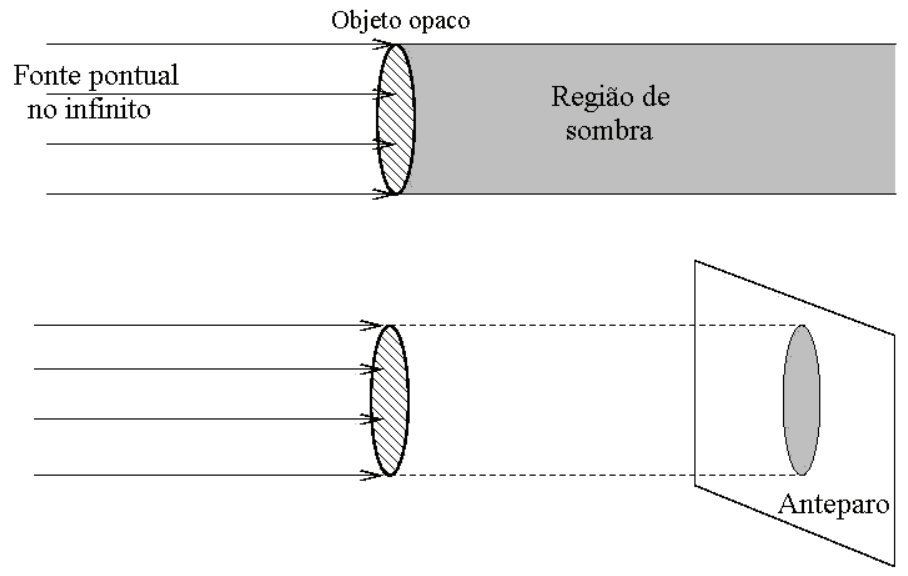

Fig. 4 - Para uma fonte pontual no infinito: região de sombra e a sombra sobre um anteparo. O tamanho da sombra não varia com a distância entre o objeto opaco e o anteparo.

\section{II.2 Sombras produzidas por fontes extensas}

Fontes extensas podem ser tratadas como um conjunto de fontes pontuais. Cada ponto da fonte extensa emite raios luminosos que, ao serem interceptados pelo objeto, geram sua própria região de sombra. Os raios originados no mesmo ponto da fonte chegam divergentes ao objeto (a divergência será tanto maior quanto mais perto estiver a fonte do objeto). O resultado será uma região composta de duas partes: a região de sombra ${ }^{6}$, que não recebe luz de nenhum ponto da fonte, e a região de penumbra, que recebe luz de alguns pontos da fonte. A penumbra é uma região de transição gradual onde a iluminação varia de um valor mínimo (sombra) até a iluminação máxima.

As Fig. 5 e 6 ilustram a geometria da região de sombra e da região de penumbra produzidas por uma fonte extensa próxima. Por simplicidade, representamos apenas os raios luminosos originados em dois pontos extremos da fonte, os quais, passando pelas bordas opostas do objeto opaco, determinam as extremidades da região de sombra e da região de penumbra. Representamos, em linha contínua,

${ }^{6}$ Também chamada umbra (e.g. Oliveira Filho e Saraiva, 2004, p. 42; Chaisson e McMillan, 1997, p.16). 
os raios provindos do bordo superior da fonte e, em linha pontilhada, os raios provindos do bordo inferior da fonte. Raios provenientes dos pontos extremos opostos da fonte chegam ao objeto opaco segundo um ângulo igual ao tamanho angular da fonte em relação à borda do objeto. Regiões atrás do objeto serão tanto mais escuras, em comparação às zonas totalmente iluminadas pela fonte, quanto mais pontos da fonte ficarem ocultos para elas.

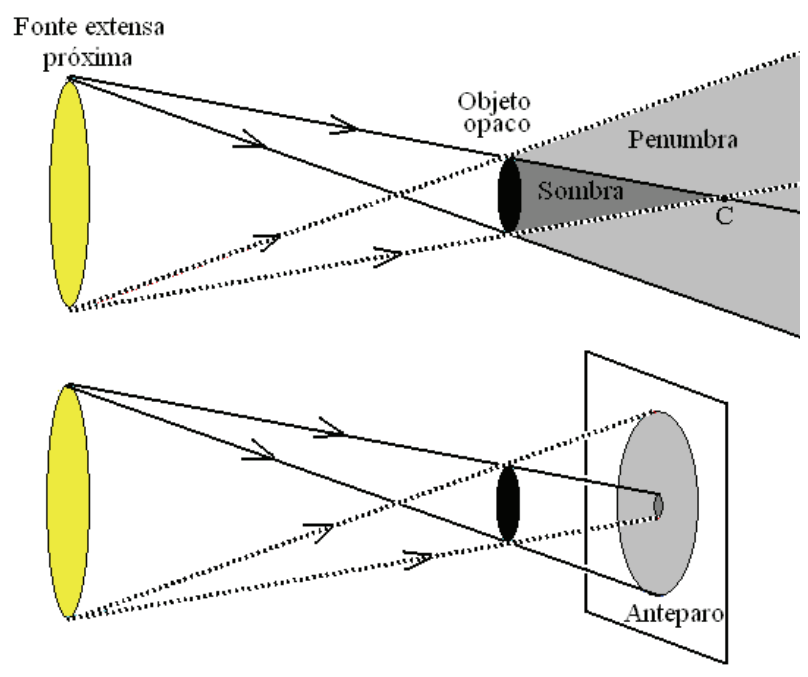

Fig. 5 - Sombra produzida por uma fonte extensa próxima e maior do que o objeto opaco que intercepta seus raios luminosos. A sombra em um anteparo é sempre menor do que o obstáculo, pois a seção transversal da região de sombra diminui conforme aumenta a distância ao obstáculo, ao passo que a seção da região de penumbra aumenta.

O tamanho e a nitidez da sombra dependem do tamanho relativo entre fonte e objeto. Se o objeto for menor do que a fonte (Fig. 5), as bordas da região de sombra são convergentes, de forma que esta região, necessariamente, se anula a uma determinada distância do objeto (ponto C na Fig. 5); para pontos mais distantes do objeto opaco que o ponto $\mathrm{C}$, existe apenas penumbra, cujas bordas são sempre divergentes. Se a fonte for menor do que o objeto (Fig. 6), as bordas da região de sombra também são divergentes e são tanto mais nítidas (isto é, terão contornos de penumbra tanto mais estreitos) quanto menor for o tamanho da fonte. 


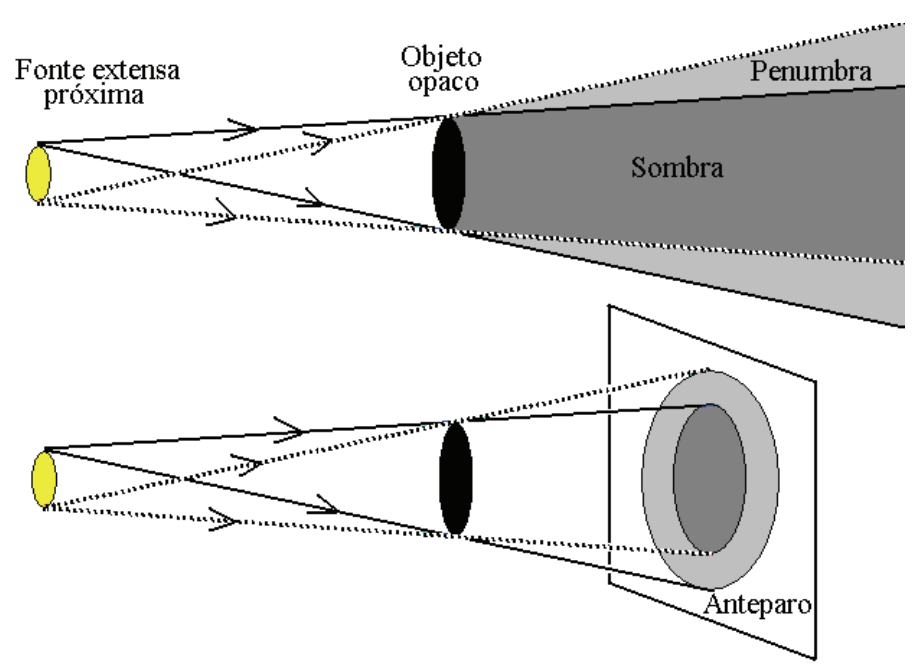

Fig. 6 - Sombra produzida por uma fonte extensa próxima e menor do que o objeto opaco que intercepta seus raios luminosos. A região de sombra é dominante sobre a região de penumbra, de forma que as bordas da sombra ficam mais nítidas. Essa nitidez é tanto maior quanto menor for a fonte.

Conforme se observa nas Fig. 5 e 6 há uma diferença importante, que depende da extensão relativa fonte-objeto. Se a fonte for maior do que o objeto (Fig. 5), a sombra deixa de existir a certa distância atrás dele, restando, além dessa distância, apenas penumbra. Se a fonte for menor do que o objeto (Fig. 6), a sombra aumenta de tamanho à medida que aumenta a distância atrás dele. A nossa vivência com sombras de obstáculos para fontes luminosas, tais como velas e lâmpadas, usualmente preenchem a condição de que a fonte é menor do que o objeto (Fig. 6) e, portanto, as dimensões da sombra aumentam com a distância que separa o obstáculo do anteparo onde vemos a sombra (conforme vemos na Fig. 1). Entretanto, esse não é o caso para as sombras de obstáculos à luz solar, como demonstraremos a seguir.

\section{Fonte maior do que o objeto a uma distância infinita do objeto: o caso do Sol}

Trataremos agora de uma fonte extensa, maior do que o objeto opaco, infinitamente distante (isto é, a uma distância muito maior do que as dimensões do 
objeto opaco). Nesse caso, a sombra produzida por cada ponto da fonte terá bordas paralelas, pois os raios provindos de um ponto da fonte, no infinito, chegam paralelos ao objeto opaco (como apresentado na Fig. 4); mas como os raios provenientes de pontos diferentes da fonte chegam ao mesmo ponto do objeto vindo de direções diferentes, o resultado é uma região composta de sombra e de penumbra, com geometria similar à do caso representado na Fig. 5.

Na Fig. 7, apresentamos a construção da sombra de um objeto opaco, menor que a fonte extensa, localizada no infinito; representamos apenas raios luminosos originados nas bordas opostas da fonte. Raios provenientes de uma borda aparecem nesta figura em linha contínua e raios originados na outra borda estão indicados por linhas pontilhadas. O ângulo $\theta$, que uma linha contínua faz com uma linha pontilhada, é o tamanho angular da fonte em relação a um ponto do objeto opaco.

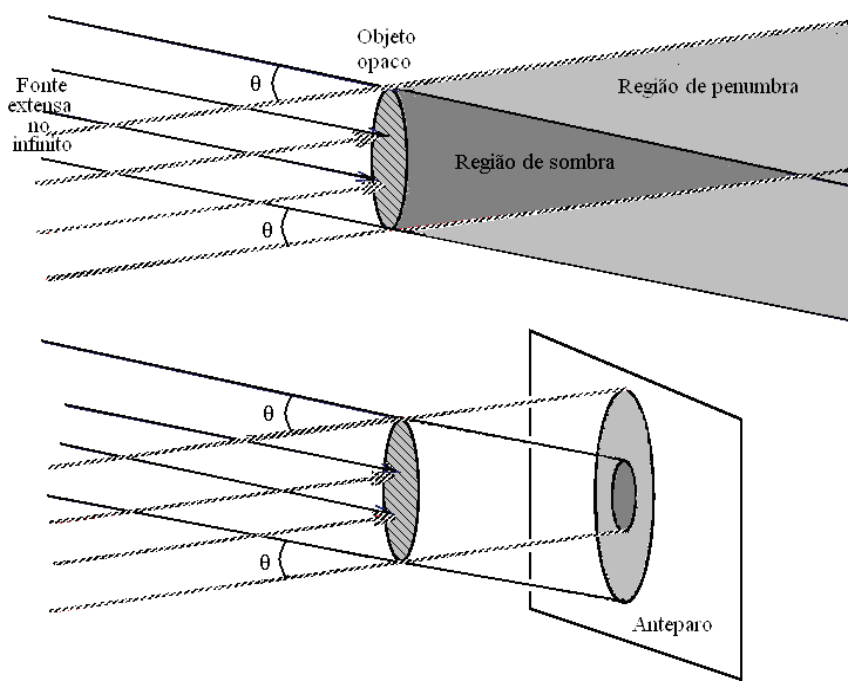

Fig. 7 - Sombra produzida por uma fonte extensa infinitamente distante. Linhas contínuas representam raios provindos do bordo superior da fonte; linhas pontilhadas, os raios provindos do bordo inferior.

Comumente vemos, em textos de Física, a representação da radiação solar chegando até nós como raios luminosos paralelos entre si. Este modelo, que considera o Sol como uma fonte pontual no infinito (Fig. 4), é adequado em muitas situações, como na explicação das fases da Lua e das estações do ano; entretanto, 
constitui-se em uma aproximação que não dá conta de diversos fenômenos ópticos interessantes, conforme pode ser visto em Silveira e Axt (2001, 2007a, 2007b).

A luz emanada de um ponto do disco solar pode ser representada por raios luminosos paralelos entre si quando atingem distâncias tão grandes quanto a que estamos do Sol, ou seja, cada ponto do disco do Sol pode ser considerado uma fonte pontual a uma distância infinita (caso considerado na Fig. 7). O tamanho angular $\theta$ do disco solar ${ }^{7}$ para um ponto na Terra é, aproximadamente, $0,53^{\circ}$. Dessa forma, raios luminosos originados em diferentes pontos do disco solar chegam até nós como raios divergentes, sendo a divergência máxima entre eles aproximadamente $0,53^{\circ}$.

Quando um obstáculo intercepta a luz solar, devido à divergência dos raios luminosos, a sombra não será perfeitamente definida, ocorrendo uma região de penumbra conforme está representado na Fig. 8, onde o ângulo subtendido pelo Sol foi exagerado para que a representação se tornasse possível. É fácil demonstrar que, sob incidência quase normal à superfície onde vemos a sombra, a região de penumbra se estende por cerca de $0,93 \mathrm{~cm}$ para cada metro que separa a borda do obstáculo da sua sombra. De acordo com a Fig. 8, a região de penumbra pode ser maior quando a incidência dos raios luminosos na superfície onde vemos a sombra ocorrer para ângulos menores do que $90^{\circ}$.

\section{Sombras que "encolhem"}

O efeito de "encolhimento" da sombra, originada pela interposição de um objeto à luz solar, pode ser facilmente previsto tendo-se em conta que os raios luminosos provenientes do disco solar são divergentes (conforme esquematizado na Fig. 7). A Fig. 9 representa um obstáculo à luz solar e a conseqüente região de sombra que ele produz. É fácil estimar que a região de sombra termina a uma distância cerca de 108 vezes maior que a extensão L do obstáculo.

Na Fig. 9, por simplicidade, estamos representando o obstáculo por uma linha ortogonal à direção de propagação do raio luminoso originado no centro do disco solar (este raio não se encontra representado na figura). Para um objeto tri-

7 A distância Terra-Sol é variável pois a órbita da Terra possui uma pequena excentricidade. A razão entre as distâncias de afélio (distância máxima entre o centro da Terra e o centro do Sol) e periélio (distância mínima entre o centro da Terra e o centro do Sol) é 1,034 e, portanto, o tamanho angular do Sol varia cerca de $1,7 \%$ em torno do tamanho médio de $0,533^{\circ}$ ou 0,00930 radiano. 
dimensional, a dimensão L deve ser avaliada como, aproximadamente, a menor extensão do obstáculo no plano que é perpendicular à direção do raio luminoso originado no centro do disco solar. Dessa forma, compreende-se que o "encolhimento" da sombra se dá porque a região de penumbra torna-se cada vez maior à medida que nos afastamos do obstáculo, reduzindo cada vez mais a sombra, até extingui-la completamente, quando tal distância for maior do que $108 \mathrm{~L}$.
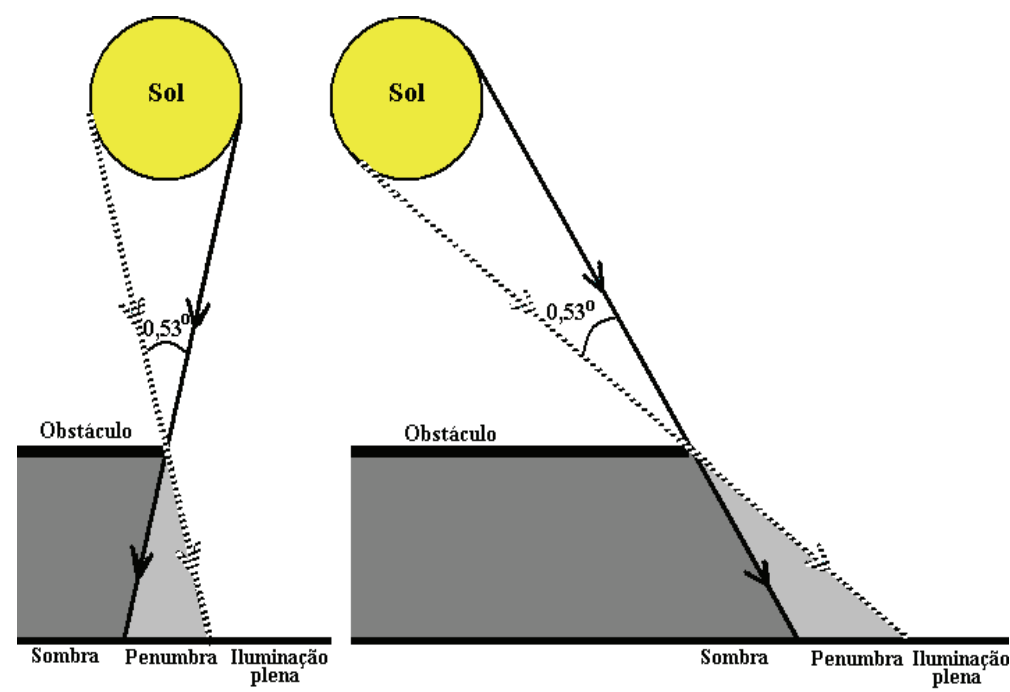

Fig. 8 - A luz solar que se origina em regiões diferentes do disco solar produz sombras com bordas não definidas, contornadas por uma região de penumbra.

Conforme discutimos na seção anterior, o que importa para que ocorra o "encolhimento" da sombra é que as dimensões lineares da fonte sejam maiores do que as dimensões lineares do obstáculo. Ora, o tamanho angular do Sol em relação ao local onde acontece a sombra pode, para um observador aí posicionado, ser pequeno se comparado com o tamanho angular do obstáculo para este mesmo observador. Os tamanhos angulares de objetos para um observador dependem também das distâncias que os objetos se encontram dele; dessa forma, um objeto aqui na Terra pode, para um de nós, ter tamanho angular muito maior do que o do Sol. Entretanto o que realmente importa para o "encolhimento" da sombra deste objeto é que as suas dimensões lineares são muito menores do que as do Sol. 


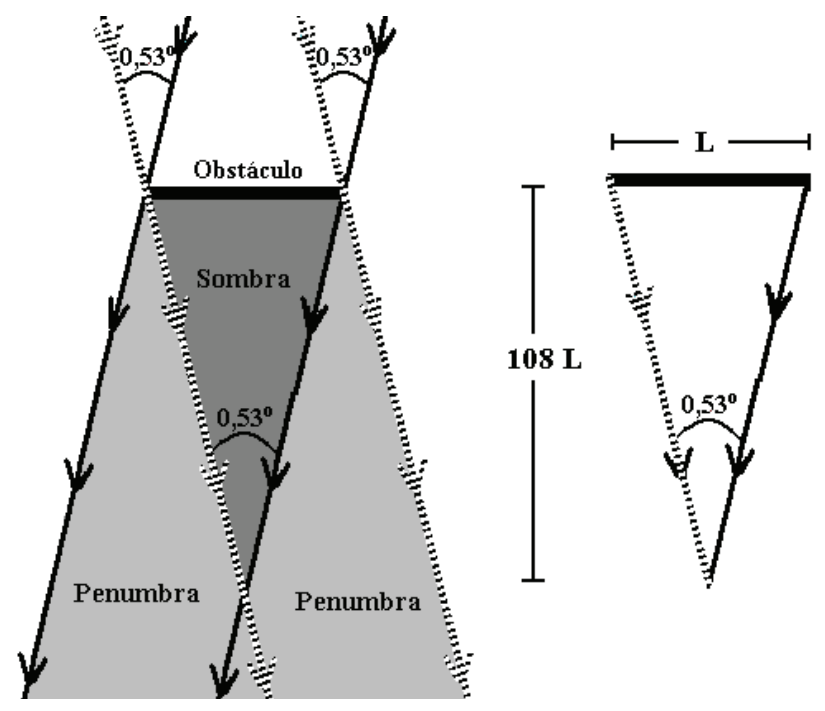

Fig. 9 - Representação esquemática da região de sombra produzida por um obstáculo que impede a passagem dos raios luminosos solares.

Na Fig. 10, vê-se a sombra de uma grade de arames sobre um piso de lajotas. No lado esquerdo da foto, o piso se encontra próximo à grade e, conforme se avança para o lado direito, a grade se afasta do piso. Observa-se que, concomitantemente com o crescimento da distância entre a grade e o piso (isto é, no sentido da esquerda para a direita), a região de penumbra em torno da sombra dos arames cresce. Na parte mais distante do piso (lado direito da foto) resta apenas a penumbra produzida pelos arames.

O efeito observado na Fig. 2, o "encolhimento" e a deformação da sombra do sujeito afastado cerca de $7 \mathrm{~m}$ da parede está agora elucidado. A largura do pulso do sujeito é cerca de $7 \mathrm{~cm}$ e a extremidade da sua mão espalmada, menor ainda; portanto, para estas regiões, o que resulta na parede distante é apenas penumbra. 


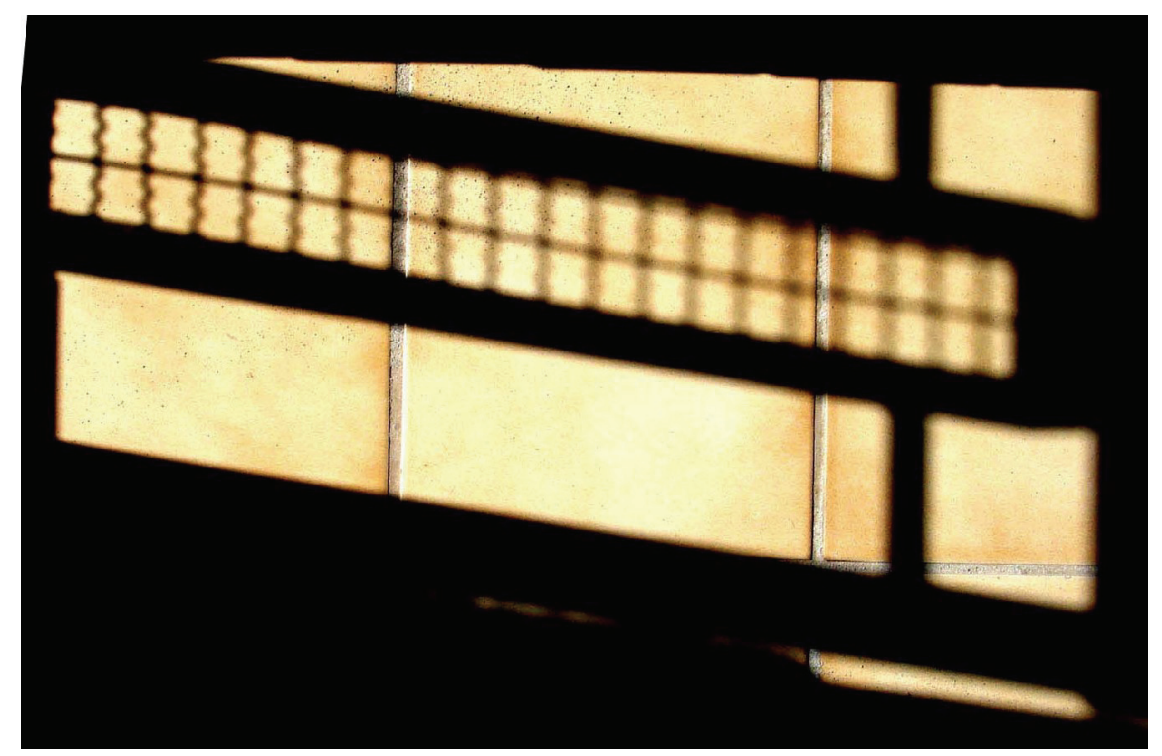

Fig. 10 - Grade de arame intercepta a luz solar produzindo sombra e penumbra.

\section{Eclipses do Sol e da Lua}

Podemos agora aplicar o que foi apresentado na Fig. 9 à Terra e à Lua quando interceptam a luz solar. Sendo estes corpos esféricos (logo, a seção transversal da sombra é circular) e muito menores do que o Sol (portanto, a sombra se estreita à medida que aumenta a distância ao objeto), suas sombras constituem cones de sombra contornados por penumbra, como mostrado também na Fig. 7.

A extensão do cone de sombra que cada um dos corpos produz é cerca de 108 vezes maior que o diâmetro do objeto opaco. Como o diâmetro da Terra é cerca de 3,66 vezes maior do que o da Lua, a extensão aproximada do cone de sombra da Lua é $29,5(=108 \div 3,66)$ diâmetros terrestres. Diferentemente da órbita da Terra em torno do Sol, a órbita da Lua em torno da Terra possui uma excentricidade não desprezível ${ }^{8}$, sendo a distância de perigeu (mínima distância entre os

${ }^{8}$ A excentricidade da órbita da Lua explica, por exemplo, que os intervalos de tempo que separam duas fases principais e consecutivas da Lua em um mesmo mês lunar sejam diferentes. Adicionalmente à excentricidade, a translação do sistema Terra-Lua em torno do Sol determina que haja variações desses intervalos de tempo de um mês para o outro. Duas fases 
centros da Terra e da Lua) 28,0 diâmetros terrestres e sendo a distância de apogeu (máxima distância entre os centros da Terra e da Lua) 31,9 diâmetros terrestres. Ou seja, o comprimento do cone de sombra da Lua é 1,5 diâmetros terrestres maior do que a distância de perigeu e é 2,4 diâmetros terrestres menor do que a distância de apogeu.

Dessa forma, ainda que em uma Lua Nova ocorra o alinhamento TerraLua-Sol (o Sol na linha dos nodos ${ }^{9}$ do sistema Terra-Lua ou muito perto dela ${ }^{10}$ ), de modo a cumprir a condição necessária para acontecer o ocultamento central do Sol pela Lua para um observador em determinada região da Terra, o eclipse do Sol poderá não ser total mas anular (isto é, o disco lunar pode não encobrir todo o disco solar, pois o cone de sombra da Lua não chegará até nós se ela estiver nas proximidades do apogeu). Caso ocorra um eclipse total, ele somente será percebido como tal por um observador dentro do cone de sombra da Lua. A intersecção do cone de sombra da Lua com a superfície da Terra em um eclipse total dar-se-á perto do vértice do cone (a Fig. 11 representa esta situação, embora os diâmetros e a distância entre a Terra e o seu satélite não estejam em escala).

principais consecutivas podem estar separadas por intervalos de tempo que variam entre 6,5 e 8,3 dias (SILVEIRA, 2001)

A linha dos nodos do sistema Terra-Lua é a linha determinada pela intersecção do plano da órbita da Terra em torno do Sol com o plano da órbita da Lua em torno da Terra. A cada 173 dias, essa linha está na mesma direção da linha Sol-Terra, ocorrendo então as temporadas de eclipses, que duram entre 31 e 38 dias (OLIVEIRA FILHO; SARAIVA, 2004, p. 46-47). Comumente, em uma temporada de eclipse acontecem um eclipse solar (parcial, total ou anular) e um eclipse lunar (parcial, total ou penumbral), separados por duas semanas.

${ }^{10}$ Como o Sol, a Terra e a Lua têm tamanhos finitos, os eclipses podem ocorrer mesmo quando os três corpos não estão perfeitamente (centro a centro) alinhados. A máxima distância angular da Lua ao nodo da órbita lunar para um eclipse solar ser possível é $18,5^{\circ}$; se essa distância for inferior a $15,4^{\circ}$ pelo menos um eclipse solar parcial certamente ocorrerá, se essa distância for inferior a $12^{\circ}$, ocorrerá com certeza um eclipse solar total ou anular (Smart, 1960, p. 381-390). O eclipse do Sol é classificado como parcial quando apenas a penumbra atinge a Terra. Mas mesmo em eclipses totais do Sol a faixa de Terra atingida pela sombra (que terá um eclipse total) é muito mais estreita que a faixa atingida pela penumbra (que terá um eclipse parcial). 


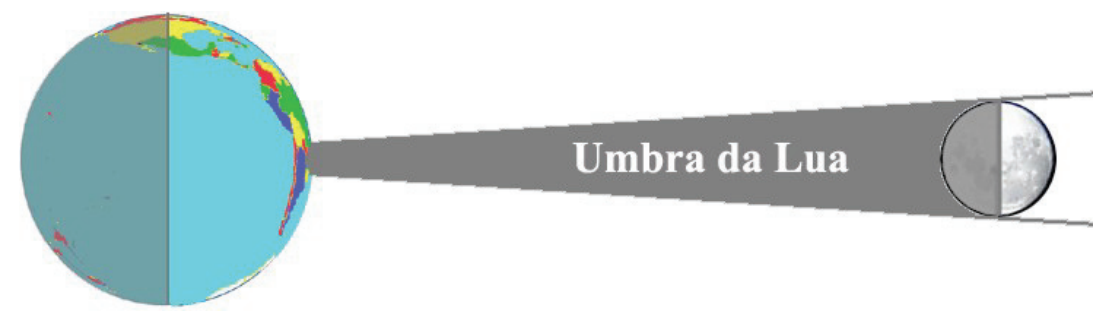

Fig. 11 - O vértice do cone de sombra ou umbra da Lua se encontra sempre próximo à superficie da Terra durante um eclipse solar total, determinando que o diâmetro da sombra da Lua na Terra seja muito menor do que o diâmetro lunar.

O diâmetro da sombra da Lua na superfície da Terra, durante um eclipse solar total, será muito menor do que o diâmetro da Lua, representando um círculo sobre a superfície da Terra com diâmetro máximo de cerca de $250 \mathrm{~km}$ apenas, em comparação aos $3476 \mathrm{~km}$ de diâmetro da própria Lua. Portanto, o fenômeno do "encolhimento" da sombra é muito pronunciado nos eclipses solares. Na Fig. 12 está representada a sombra da Lua na Terra, em escala compatível com a escala do diâmetro da Terra.

Quando em uma Lua Cheia acontecer o alinhamento Lua-Terra-Sol, o cone de sombra da Terra sempre atingirá a órbita da Lua, pois a sua extensão é muito maior do que a distância de apogeu da Lua, acontecendo então um eclipse total ${ }^{11}$ da Lua. O diâmetro do cone de sombra da Terra à distância da Lua é facilmente calculável e se situa em valores próximos a 0,7 diâmetros terrestres ou 2,6 diâmetros lunares (a Fig. 13 é uma representação das condições para a ocorrência de um eclipse lunar total, embora os diâmetros e as distâncias entre os três corpos não estejam em escala). Vale notar que Aristarco de Samos (vide a nota de rodapé 2),

11 Para a Lua entrar no cone de sombra da Terra e acontecer um eclipse lunar total, a máxima distância angular entre a Lua e o nodo da órbita lunar deve ser menor do que $4,6^{\circ}$; se a distância for maior do que isso, mas menor do que $10^{\circ}$ acontecerá um eclipse lunar parcial, quando apenas parte da Lua atravessa a região de sombra (OLIVEIRA FILHO; SARAIVA, 2004, p. 46-47). 
três séculos antes de Cristo, já estimava em cerca de dois diâmetros lunares o diâmetro do cone de sombra da Terra na região onde passa a órbita da Lua.

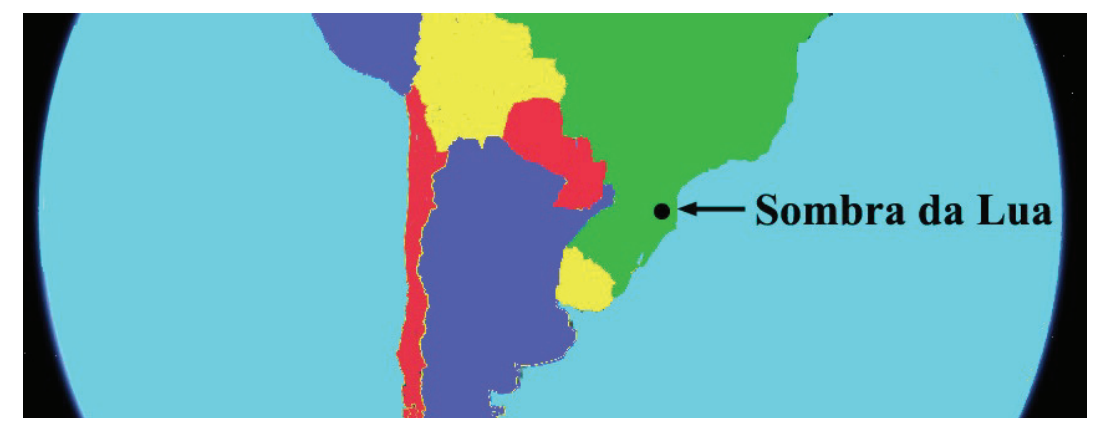

Fig. 12 - A sombra da Lua na superficie da Terra durante um eclipse solar total tem um diâmetro com no máximo cerca de $250 \mathrm{~km}$. Somente observadores dentro dessa sombra "encolhida" poderão perceber o eclipse como total.

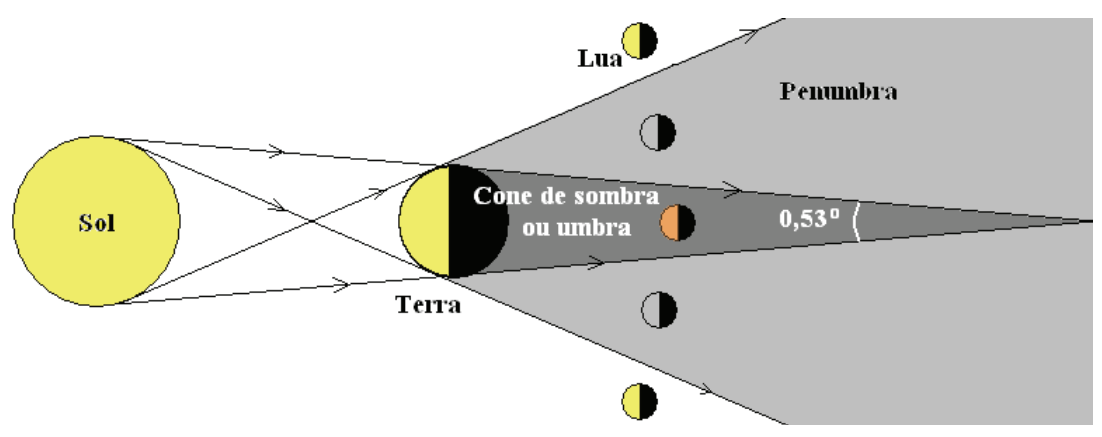

Fig. 13 - O diâmetro do cone de sombra da Terra perfaz cerca de 0,7 diâmetros terrestres ou 2,6 diâmetros lunares na região onde orbita a Lua.

\section{Conclusão}

Neste artigo tratamos de um interessante efeito que pode ser percebido na sombra de um objeto que barra os raios luminosos originados no disco solar. Justificamos teoricamente, ilustrando com fotografias e diagramas, que a sombra se deforma gradualmente conforme ela se afasta do objeto, finalmente desaparecendo, 
substituída por penumbra. Mostramos que o "encolhimento da sombra" acontece sempre que a fonte luminosa é extensa e maior (em dimensão linear) do que o objeto opaco iluminado.

Apesar de o efeito ser bem conhecido no contexto da Astronomia, mais especificamente nas discussões sobre os eclipses solares e lunares, ele nos impressiona quando o vemos acontecer com objetos do nosso cotidiano. A inusitada deformação das sombras pode servir de motivação para o ensino da Óptica Geométrica, na medida em que evidencia a importância dessa disciplina para melhorar a percepção e o entendimento do mundo à nossa volta.

\section{Agradecimentos}

Agradecemos à Prof ${ }^{\mathrm{a} .}$ Maria Cristina Varriale do IM-UFRGS e à Prof ${ }^{\mathrm{a}}$. Maria Terezinha Xavier Silva do IF-UFRGS pela leitura crítica deste artigo e pelas sugestões apresentadas. Da mesma forma, agradecemos aos pareceristas pelas suas sugestões.

\section{Referências}

BERRY, A. A short history of Astronomy. New York: Dover Publications Inc, 1961.

CASATI, R. A descoberta da sombra. São Paulo: Companhia das Letras, 2001.

CHAISSON E.; McMillan, S. Astronomy Today. 2. ed. Prentice Hall Inc, 1997.

HEATH, T. Aristarchus of Samos - The ancient Copernicus. New York: Dover, 1981.

HOSKIN, M. (Ed.). The Cambridge Concise History of Astronomy. Cambridge: Cambridge University Press, 1999.

KNILL, D.; MAMASSIAN, P.; KERSTEN, D. Geometry of Shadows. J. Opt. Soc., Am. A., v. 14, n. 12, p. 3216-3231, 1997.

MOONHOAX $<\underline{\text { www.redzero.co.uk }}>$ 2003. Disponível em:

$<$ http://www.redzero.co.uk/moonhoax. $>$. Acesso em: 14 nov. 2007. 
MSSS (Malin Space Science Systems). Mars Global Surveyor - Mars Orbital Camera. San Diego: MSSS, 2001. Disponível em:

$<$ http://www.msss.com/mars_images/moc/01_31_01_releases/cydonia/> Acesso em: 14 nov. 2007.

NASA. Astronomy picture of the day. 1998. Disponível em:

$<$ http://apod.nasa.gov/apod/ap980407.html >. Acesso em: 14 nov. 2007.

OLIVEIRA FILHO, K. S.; SARAIVA, M. F. O. Astronomia e Astrofísica. 2. ed. São Paulo: Editora Livraria da Física, 2004.

SILVEIRA, F. L. As variações dos intervalos de tempo entre as fases principais da Lua. Revista Brasileira de Ensino de Física, São Paulo, v. 23, n.3, p.330-307,

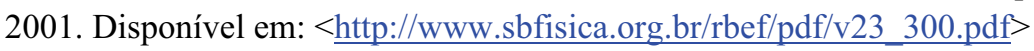

SILVEIRA, F. L.; AXT, R. O que vemos quando projetamos a luz do Sol com um espelho plano: manchas luminosas ou imagens? Caderno Catarinense de Ensino de Física, Florianópolis, v. 18, n. 3: p. 364-375, dez. 2001. Disponível em: $<\underline{\text { http://www.fsc.ufsc.br/ccef/port/18-3/artpdf/a7.pdf }>~}$

A "atração" entre as sombras! A Física na Escola, São Paulo, v. 8, n. 1, p. 17-21, 2007. Disponível em:

$<$ http://www.sbfisica.org.br/fne/Vol8/Num1/v08n01a04.pdf >

O eclipse solar e as imagens do Sol observadas no chão ou numa parede. Caderno Brasileiro de Ensino de Física, v. 24, n. 3, p. 353-359, dez. 2007.

SMART, W. M. Text-Book on Spherical Astronomy. 6. ed. Cambridge: Cambridge University Press, 1960.

VERDET, J. P. Uma história da Astronomia. Rio de Janeiro: Zahar, 1991. 